conference had 1 or more financial connections with the manufacturers of hernia devices and implements. ${ }^{2}$

The choice of one's own patients to carry out the present study is, to my thinking, not a well thought-out design. Is it far-fetched to think that a patient in one's own clinic may be intimidated? Would the patients find it difficult to be objective? Can such a patient assess the quality of treatment and the integrity of a surgeon? Of an industry? Of a financial interaction between the last 2 entities? Can a patient not be concerned of a possibility of retribution in the quality of care? Not only is it not a multivariate proposal, but also one bordering on psychological testing, which has been difficult of late to duplicate with any accuracy.

It may be of interest to add that the US Food and Drug Administration itself is facing its own set of conflicts of interests, abundantly covered in the lay press. Dr. Jeff Shuren (a lawyer and physician), who is in charge of the devices division that vets various polypropylene and other gadgets in hernia and other surgeries, is married to a lawyer who is an established lobbyist for the industry that manufactures the very items that her husband has to approve or reject!

The assistant chief to Shuren recently proposed by President Obama is Robert M. Califf, a former "Big Pharma" mega-lobbyist who received millions in funding and salary support."

Despite the honest intent of the University of Toronto group, their dutiful call on the ethical teams and sundry support from their venerable institution, I find it difficult to believe their conclusions, and without malice I must quote the insightful Scottish poet Andrew Lang: "politicians use statistics in the same way that a drunk uses lamp-posts - for support rather than illumination."

\section{Robert Bendavid}

Department of Surgery, Shouldice Hospital \& University of Toronto, Toronto, Ont.

\section{DOI: 10.1503/cjs.015715}

\section{References}

1. Camp MW, Gross AE, McKneally MF. Patient views on financial relationships between surgeons and surgical device manufacturers. Can 7 Surg 2015;58:323-9.

2. Bendavid R. Hernia societies - A blessing or a curse? Who is running them? Ethical surgeons or the industry. Int 7 Clin Med 2014;5:766-9.

3. Wedler C. Obama's new appointee to head the $\mathrm{fda}$ is a big pharma mega-lobbyist. MintPress News 2015 Oct. 19. Available: www.mintpressnews.com/obamas-new -appointee-to-head-the-fda-is-a-big -pharma-mega-lobbyist/210458/ (accessed 2015 Nov. 3).

\section{Patient Views on financial RELATIONSHIPS BETWEEN SURGEONS AND SURGICAL DEVICE MANUFACTURERS: AUTHOR RESPONSE}

Like Dr. Bendavid, we were concerned about the potentially confounding effect of social desirability response bias $^{1}$ (the desire of study participants to please and be treated favourably by the research team). We tried to mitigate this bias by informing patients that their participation was entirely voluntary and that their current and future care would not be affected by being interviewed. Patients were told that interviews were confidential and that their surgeon would never have access to their interviews, nor be aware that they had been interviewed. Their surgeon was not involved in analyzing or collecting the data. We excluded preoperative patients, who might more easily be intimidated or worried by the implied suggestion that their care could be subordinated to industry interests.

Dr. Bendavid's concerns regarding the methodology used in our study reflect unfamiliarity with qualitative research. Qualitative methods are uniquely valuable for examining areas that are not amenable to quantitative methods, such as complex social phenomena with multiple variables that are difficult to control (beliefs, behaviours and attitudes). ${ }^{2}$ In qualitative research, convenience sampling is used initially to get a general sense of the problem, as viewed by the participants. As analysis proceeds during the collection of data, convenience sampling ceases as concepts and themes that emerge guide purposive recruitment and subsequent research. The reproducibility and trustworthiness of our findings meets recognized standards for qualitative research. ${ }^{3}$

Based on our qualitative exploration, we completed a quantitative survey of more than 500 postarthroplasty patients in Canada and the United States. ${ }^{4}$ In total, 502 patients from 3 centres and 15 surgeons' clinics completed selfadministered questionnaires. The results from this quantitative study support and expand the findings from our qualitative study. ${ }^{5}$ The element of patient intimidation was diminished by geographic and professional distance from the authors of the qualitative study.

The problems at the interface of surgery with industry are well described by Dr. Bendavid in his own field. Our goal in this research was to bring the common sense voice of experienced patients into the discussion. We recognize our patient participants' approval of certain financial relationships between surgeons and industry does not mean that these relationships are morally acceptable. ${ }^{6}$ However, we believe the results of this qualitative research and its quantitative complement will add the patients' perspective, helping surgeons develop appropriate management of their 
financial relationships with industry and strengthening the public's trust in our profession.

We thank Dr. Bendavid for giving us the opportunity to explain how we have dealt with the issue of potentially biased responses from our patient participants. His understandably biased comments about industry help illustrate the problem we are working to clarify in this study, using as our reference standard the common sense views of patients reflecting on their surgical experiences. We enjoyed the humour of Andrew Lang's analogy to the staggering drunkard, but we believe our University of Toronto col- leagues' often sharp critiques served not as supporting lamp posts but as illuminators, strengthening our study by their thoughtful assessment.

\section{Mark Camp MD; Allan Gross MD; Martin McKneally MD}

From the Hospital for Sick Children, Toronto, Ont. (Camp); Mount Sinai Hospital, Toronto, Ont. (Gross); and the University of Toronto, Toronto, Ont. (McKneally).

DOI: $10.1503 /$ cjs.015915

\section{References}

1. Chow A, Mayer E, Darzi A, et al. Patient satisfaction in surgery. In: Key topics in surgical research and methodology. Athanasiou $\mathrm{T}$, Debas H, Darzi A, eds. Springer, New York, 2010. p168.

2. Pope C, Mays N. Reaching the parts other methods cannot reach: an introduction to qualitative methods in health and health services research. BMF 1995;311:42-5.

3. Beck CT. Qualitative research: The evaluation of its credibility, fittingness, and auditability. West 7 Nurs Res 1993;15:263-6.

4. Camp MW, Mattingly DA, Gross AE, et al. Patients' views on surgeons' financial conflicts of interest. F Bone Foint Surg Am 2013;95:1-8.

5. Camp MW, Gross AE, McKneally MF. Patient views on financial relationships between surgeons and surgical device manufacturers. Can 7 Surg 2015;58:323-9.

6. McGrath PJ. Analysis: An introduction to ethical concepts. 'Is' and 'ought'. $7 \mathrm{Med}$ Ethics 1975;1:150-1. 